\title{
From technology transfer to participative design: a case study of pollution prevention in South African townships
}

\author{
W van Niekerk \\ School of Mechanical Engineering, North West University
}

\begin{abstract}
Since the 1960's several unsuccessful attempts were made to reduce air pollution in South African townships. These efforts targeted coal fires and included devolatalised coal, low-smoke stoves and electrification. All these efforts were more or less prescriptive in nature, technology driven and shared a common view of the role of technology. In this paper a different approach is described that had very good results. This approach starts at the coal user and their preferences and does not try to change their behaviour or attitude by means of education or coercive measures. This was done because after several years of involvement with coal and wood using communities, a good understanding was developed of the role of fire in the household and the context in which possible solutions must function. Also, the user of the technology is made a full partner in the problem solving process. This approach resulted in the adaptation of an alternative method to light a coal fire. The adapted method enjoys widespread acceptance and can reduce the contribution of coal fires to air pollution by $50 \%$. Plans are under way by the South African Government to introduce communities nationwide to this method.
\end{abstract}

Keywords: air pollution, devolatilised coal, lowsmoke stoves low-smoke fuels, electrification, eMbalenhle Air Quality Project

\section{Introduction}

The term technology transfer is used in a variety of disciplines and its meaning is therefore somewhat diffused. Usually it describes the process of making the users of technology (in the widest sense) in one sector aware of technology that was developed or invented in another sector with the goal of getting the users to apply or market the technology. In the medical field, it can mean getting practitioners to implement a new, unknown or strange treatment correctly (McCarty et al 2004).

In the development of communities and countries, technology transfer is often seen as important because of the belief that the lack of development is essentially due to the lack of technology (Dalla Palma \& Zein 2004), and the assumption that new technology will be spontaneously accepted by developing communities and so solve the underdevelopment problem. In the last decade or so, it has become clear that the development process is much more complicated. From the literature it is clear that a different approach has been developing on different levels. Dalla Palma and Zein (2004) state: 'Thus participative approaches of technology (transfer) focus on humans rather than on technology and actively involve users not as beneficiaries but as actors in search of their own development and solutions.'

Even the United Nations is adapting their approach and discuss at length 'The need for participatory approaches' in a document titled: 'Methodological and Technological Issues in Technology Transfer' where it is stated: 'Participatory development is now widely recognized as a way of achieving technology transfer at all levels of development endeavour' (IPCC, UNEP 2000).

The combating of pollution in townships illustrates very clearly the shortcomings of the traditional approach to technology transfer and also the potential success of a new approach developed by the NOVA Institute (see note at end). The new approach takes participation to the level of the individual, the users of the technology, and make them partners in the problem solving process. Even though the goal may be the implementation of a new way of doing things, in this new approach, the technology is initially still undefined, and the process is open - therefore the term participative design. This is fundamentally different from traditional technology transfer processes where the goal 
is usually the transfer of a specific technology.

This paper describes the history of pollution prevention efforts in townships. The initial efforts were largely unsuccessful in reducing air pollution. An attempt is made to identify reasons for this failure. Then the process followed in the development of a cost-effective, beneficial and acceptable method is described. The new method drastically reduces the smoke generation of coal fires. The implementation of the method reduced the contribution of coal fires to air pollution in eMbalenhle, a township near Secunda, by $50 \%$. The Department of Mineral and Energy is planning to introduce communities nationally to the method. At the moment it seems to be the best (if not only) successful example of its kind in the country and valuable lessons can be learnt from studying the approach.

The paper is an interpretation of the work done by the NOVA Institute as reflected in the reports of projects done for SASOL Synthetic Fuels and for the Department of Minerals and Energy. It is the result of a literature survey that included these reports, discussions with people involved in these projects and personal involvement with other studies NOVA have done.

\section{Initial efforts to reduce air pollution}

The burning of coal in townships causes indoor pollution levels that are 2-3 times over the acceptable levels in summer and 6-7 times in winter. Several efforts were made over time to reduce this pollution:

\section{a) Devolatilized coal}

In the 1960's devolatilized coal was investigated as a method to reduce air pollution. Not much is known about this effort, but one can conclude that it was not a success, because it was followed by the low-smoke stove initiative (van Niekerk \& Swanepoel 2002).

\section{b) Low-smoke stoves}

The Air Pollution Prevention Act of 1973 and 1981 prescribed certain requirements for new stoves with regard to durability and performance. In most cases this led to manufacturers adapting the standard cast iron stoves by inserting a dividing brick or plate into the combustion chamber to create a secondary combustion chamber where un-burnt volatiles are burned.

The initiative was largely unsuccessful. The perceived reason, namely that the users were to blame because they modified the combustion chamber (by removing the dividing brick or plate), is not necessarily correct. During investigations, stoves were found with the bricks still intact. Some people were even looking for bricks to replace damaged ones. It appears that the problem could be with the design of the solution, not with the behaviour of the end- users ((van Niekerk \& Swanepoel 2002).

\section{c) Electrification}

The National Electrification Drive (NED) was announced in 1991 by ESKOM, the South African Electricity Utility Company, the aim being to electrify 3 million houses in 5 years (van Niekerk \& Swanepoel 2002). However, after electrification there is often a switch back to coal and even paraffin because electricity does not satisfy all needs. Electricity is often used for lights, TV, etc., and not so much for space and water heating. Existing coaland wood-based methods are still used for space heating. The result is that pollution levels have not decreased significantly.

During a study of the impact of electrification, a survey was done in 1023 houses in eMbalenhle (van Niekerk \& Swanepoel 2002). The following became clear:

- As the quality of the house improves (more expensive insulation, brick walls, electrification) the use of coal increases as does the total energy cost of the household. An increase in income did not lead to a switch from coal to electricity, but rather to an increased usage of both. This indicates that coal satisfies certain needs that are not being satisfied by electricity. These needs could be of a social, religious, physical or other nature.

- In informal houses (with and without insulation) electrification makes no impact on the levels of coal usage. This was also found by Davis and Ward in 1995.

\section{d) Low-smoke fuels}

In the 1990s the (then) Department of Mineral and Energy Affairs (DME) initiated an investigation into low-smoke fuels (LSF), which were regarded as transitional fuels 'until electricity becomes the preferred energy source'. Penny Hoets, a consultant, conducted several social acceptability studies for the DME, first on a smaller scale, and in the end culminating in an extensive study using 500 questionnaires during the Macro-Scale Experiment in Qalabotjha, Villiers, during the winter of 1997 (Hoets 1997; Palmer 1998) The results are analysed in two reports (Scorgie et al 2001; Qase et al 2001).

At the end of the study it was concluded: 'No single fuel is currently identifiable as comprising all of the attributes necessary to present a viable alternative to the use of bituminous coal within the household energy sector' (Scorgie et al 2001). The required attributes were: Low emissions, potential for health benefits, social acceptability, technical feasibility and economic viability. Social and technical requirements were: Suitable heat production and retention, speed of cooking and ease of ignition. Coal merchants also reacted negatively to low smoke fuel, a product that they perceived as a 
threat to their market (van Niekerk \& Swanepoel 1999).

The Net Present Value (cost in present day terms) of implementing LSF is estimated to be R36 000 million while the Benefit/Cost ratio (ratio of monetary benefit in terms of savings in anticipated health costs as result of reduced air pollution levels attributable to effective implementation, to the cost of implementation,) is estimated to be 0.4 (Bentley West and Airshed Planning Professionals (2004). This means that the anticipated benefit is less than the cost of implementation.

An issue that is also important is the relation between the fuel and the stove. The smoke formation is influenced by the interaction between the two factors so that a low-smoke fuel cannot be called such in isolation from the stove in which it is burned.

\section{Discussion of these efforts to reduce air pollution}

It is important to look at some underlying assumptions in these efforts to reduce air pollution and try to identify some commonalities.

All these efforts were based on the assumption that the problem will be solved by simply introducing a better way of doing things - a way that was known to the people outside the community. They were therefore prescriptive in nature. It stems from a belief by the service providers that they had a sufficient understanding of the needs, wants and expectations of the coal using community.

For instance, the low smoke stoves were merely prescribed by law, without engaging the end users concerning their needs and requirements. The basic stove design that remained unchanged for about fifty years were used. No provision was made for the needs of township residents, like space heating and the ability to burn wood (which requires front loading) or the effect of lower roofs, leading to shorter chimneys or affordability in instances where income was often less than R200 per month.

Initially in the National Electrification Drive (NED), the same technology used in middle-class suburbs, was used. Little effort was made to determine the specific circumstances of the consumer and to design user-friendly technology. When users started the rent boycott, it was initially seen as a purely political problem. Later on pre-payment meters were introduced in an effort to solve the problem of non-payment.

It can also be said that these efforts were technology driven (van Niekerk \& van Niekerk 2000). Sometimes a product functions properly, is economical and can solve a certain problem. Such a product could, nevertheless, be poorly received by the end-user. In the case of a technology-driven solution, the reaction of the service or product provider is then to try and change the people who must use the product (rather than the product itself). If, for example, the problem is user resistance, the solution is sought in education and the changing of attitudes - as with the Masakhane project. It is assumed that the user will change once he or she has received the required education or it is assumed that the user can be coerced to change - for instance by cutting the electricity supply or installing tamper proof pre-payment meters and distribution boxes.

The NED was also intended as a method to modernize the community (van Niekerk \& Swanepoel 2002). The desire of all people to modernize along Western lines is often assumed without question. A new, more modern way of doing things would therefore be spontaneously implemented and the old way of doing things, abandoned and discouraged. Coal was seen as a transitional fuel and it was expected, that in the modernization process, the other energy carriers like wood, paraffin and gas would gradually disappear and that there would be a spontaneous movement away from coal (van Niekerk \& Swanepoel 2002). However, this assumption is not completely valid.

In the 90's several researchers took the trouble to ask people in low income communities where coal was used, what their views, needs and perceptions were (van Niekerk \& Swanepoel 2002). These researchers were sometimes unaware of each other, but came to remarkable similar results. Hoets (1995) and van Niekerk (1998) both found that a variety of social and/or cultural factors influence decisions on fuel use. Both point out that it is a mistake to assume that electricity and western modernization are the destination that all people are moving towards.

The emotional, religious and social significance of the coal stove and/or fire became apparent in interviews. The intensity of feelings can be seen in statements such as:

'My coal stove is my life, without it my life would be meaningless because I won't be able to make a warm house, cook, heat water for my children or iron for them' (Hoets 1995).

'Even if there is no food, but there is fire, I am still happy, because the stove brings the family together' (van Niekerk 1998).

During the DME's Macro Scale Experiment in Qalabotjha in July 1997, a representative sample of households were asked what they liked about the coal stove, and a number of possibilities were mentioned to which people could respond. It is interesting to note that $80 \%$ of the respondents indicated that they intended to keep their coal stoves in spite of the fact the $83.6 \%$ 'agree a lot' that the smoke of the stoves are bad for their health (van Niekerk \& 
Swanepoel 2002).

The Low Smoke Fuel Programme (LSFP) differed in an important aspect from the other attempts. It could still be seen as somewhat prescriptive and technology driven, but it engaged the end user in the search for a suitable solution. It maintained an excellent balance between the focus of the programme (making suitable low smoke fuel available) and openness to other alternative possibilities that could suddenly appear and either solve the whole problem or derail the process. Eventually this openness made a better understanding of the problem possible.

\section{The eMbalenhle Air Quality (MAQ) Project}

Towards the end of 1997, SASOL Synthetic Fuels commissioned NOVA to draw up a strategy to reduce air pollution in eMbalenhle, a township near their factory in Secunda. The development of this strategy and the subsequent work provided the opportunity to refine a new approach, substantially different from the previous approaches. This new approach made it possible to design a method that drastically reduced air pollution. This approach will now be briefly described.

\section{Phases of the project}

This project proceeded in phases where field research played an important role. This is in contrast to other projects where implementation often follows shortly after a decision is taken to help a community and no or very little research is done. In this project however, the intensity of research and implementation differed in different phases.

Although phases sometimes overlapped somewhat, it is important to distinguish between them. Initially almost all activity is focussed on research and implementation gets very little attention. As the project proceeded, less research was done and implementations got more attention. Finally during full scale implementation, research only had a support and monitoring function.

The goal was established first. In the MAQ project this was determined by SASOL who wanted a strategy to lower pollution levels. All role players from outside the community, and the community members at grassroots level, as well as community leaders, put their heads together until they had a common understanding of the problem. They jointly formed a steering committee that met once a month.

In the needs driven approach it is also important that the role players consider and reach consensus on the requirements a product should conform to. Examples of such requirements are:

- Functionality - The product must function properly and be easy to use.

- Affordability - The ability and willingness of the end user to pay for the solution, and if not, for another party (local or national government) to do so. Potential savings can be for the individual household or for the local or national government.

- Beneficiality - The extent to which the solution does not merely replace the problem with another problem elsewhere, or create new problems in other areas or spheres of the household or community.

- Cost-effectiveness - The solution must offer good value for money.

- Desirability - Evidence that the end-users will spontaneously implement the specific solution and continue to do so is an indication that the solution is desirable.

- Sustainability - Evidence that the users will maintain and continue to use the solution (social sustainability), that users will be able to afford the solution in the longer term (financial sustainability) and that the solution has no detrimental impact on the ecology (ecological sustainability).

Then a research phase followed. The MAQ project tried to understand the interaction between technological and human factors. To do that, quantitative research was conducted where the effectiveness of several selected solutions were determined, as well as qualitative research, which tried to understand what the end-user really wanted, needed and desired with reference to energy products.

From the research results, it became clear that insulating the houses was effective in reducing pollution levels and that users reported huge reductions in coal consumption. The desirability was also very high. People felt it helped to keep dust out of the home and helped to 'create a real home'. However, no affordable and safe insulation material that also complies with the other criteria was available at that stage.

It was also found that many of the households in eMbalenhle used the 'imbaula' for space heating and cooking purposes. The imbaula is a tin drum (usually an empty 50 litre paint drum) with holes in the side (made by the owner), filled with coal. The imbaula is often the most important cause of pollution. Yet it is highly unpopular because it is expensive to use and wasteful. Some of the respondents use up to $15 \mathrm{~kg}$ of coal at a time and leave the imbaula outside for up to 2 hours after ignition for it to heat up properly and stop smoking. The fact that households continue to use the imbaula despite its obvious drawbacks is not surprising and in line with the insight gained into the important role of fire in the township household.

It was decided to investigate the acceptability of a different way of lighting the imbaula (the topdown lightning method). This method almost completely eliminates smoke formation, does not need 
subsidies and saves people significant amounts in coal consumption - between 25 and $50 \%$. It also works well in coal stoves. A disadvantage is that it is different from the way people have been making fire for generations and most people think it will not work. (Apparantly there has been efforts to promote this method in townships by means of pamphlets with no success.) Ten trained fieldworkers demonstrated it at different homes in the township, but the general feedback was that the new method didn't work. However, one grandmother modified the procedure a bit. She put a few pieces of coal on top of the paper and wood that was already on top of the bulk of the coal - and reported success.

The adapted way of lighting the fire proved to be the breakthrough in community acceptance of the method, which was promptly named Basa Magogo ('make fire like grandmother'). The acceptability was confirmed when the method was introduced to 1000 households in the year 2000. This method conformed to all the criteria of acceptability, desirability, beneficiality etc. In controlled lab experiments, the particulate emissions from coal in the Basa Magogo fires were on average $78 \%$ lower than the particulate emission from coal in the conventional bottom-up fires and used less coal (Le Roux et al 2005). In Figure 1 a picture taken during the testing, is shown. This was the end of the evaluation, validation and refinement phase.

Next followed the pilot implementation phase (The Basa Njengo Magogo Project Team 2002). The method was evaluated at other townships Zamdela, Sasolburg and Orange Farm. The acceptance by these communities was in line with the figures from eMbalenhle. To date $55 \%$ of the eMbalenhle community have started using the new method and there has been a $38 \%$ improvement in total air pollution, or about $50 \%$ reduction in pollu- tion caused by domestic coal use.

The adapted method to light a coal stove reduces the fuel cost of households and also the medical costs (to government) because of lower levels of upper respiratory infections. The Benefit/Cost ratio is between 120 and 170 , and the implementation cost is between R4 million and R8 million (Bentley West and Airshed Planning Professionals 2004).

It appears that about $40 \%$ to $50 \%$ of users do not switch over to the top-down method of ignition. The reason why this is the case is under investigation at the moment. It is assumed that a better understanding of the motivational patterns of coal users will make it possible to achieve a reduction in air pollution caused by coal use by a further $30 \%$ from the original levels - therefore, in total an $80 \%$ reduction in the contribution by coal.

The next phase is full scale implementation. The government requested NOVA and Palmer Development Group to propose a strategy for national, full scale implementation.

\section{Discussion of the success of the $M A Q$ project}

Instead of using a prescriptive, technology driven approach, NOVA followed a needs driven approach (van Niekerk \& van Niekerk 2000). A needs-driven approach takes the user seriously and starts with the needs of the user, and then searches for a solution that will satisfy these needs within the context of the user. The user can be introduced to one or more products that may solve the problem in order to get a reaction and stimulate discussion. From the discussion it may become clear what needs the product can (or cannot) fulfil and how the product will fit into the life (lives) of the user(s). The emphasis is then on changing the design of the
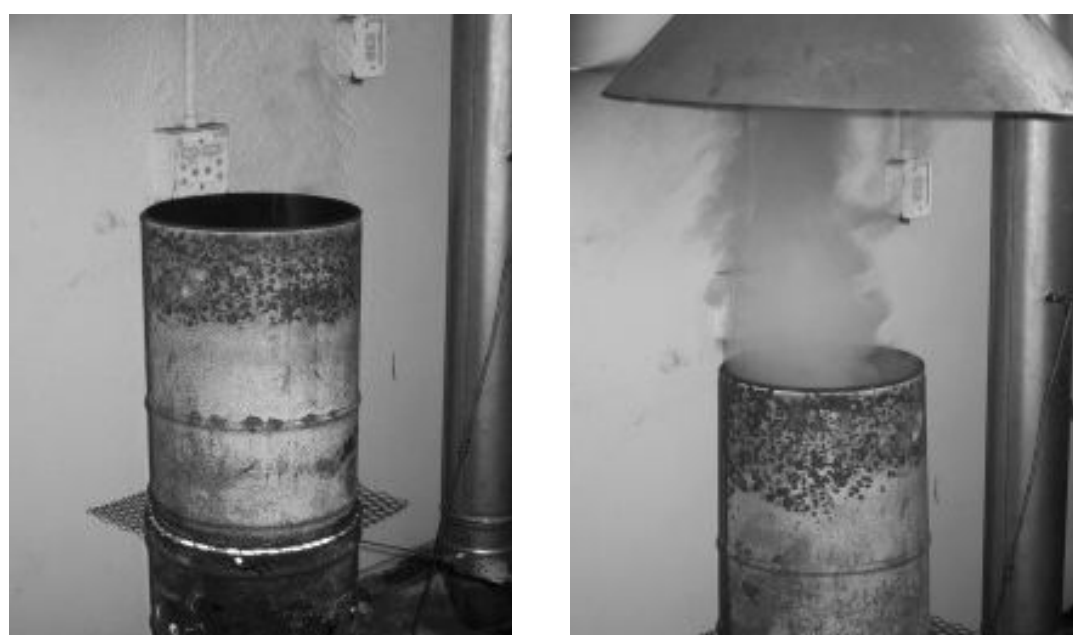

Figure 1: Comparative smoke emissions from the Basa Magogo fire (left) and the fire ignited with the bottoms-up method (right) Source: CSIR Report 
product (or designing a new product) in an effort to meet the needs of the user. This approach bridges the gap between the coal users on the one side and the suppliers of the technology on the other side (the government, industry or scientific community).

Proper attention was given to research. Research is often neglected in favour of implementation. This can be a costly mistake. The R3 million that was spent on research for this project must be compared to the estimated R3 600 million that will be necessary to implement the LSFP (Bentley West and Airshed Planning Professionals 2004). Firstly, research meant understanding the context properly. This understanding only came after a long involvement with the users of coal and a thorough understanding of the problem. By not trying to do away with the coal fire, probably made for easier acceptance of the new method of lighting the fire.

Another aspect of research was searching for the right technology until an acceptable solution was found. When initial results indicated that insulation does not comply with all requirements, another option was investigated. Only when an acceptable option was found, did the next phase commenced.

Participative design - It is generally accepted that it is important to understand the context in which a certain technology must function. In this project a further step was taken i.e. making the user part of the design process. This meant that the researchers took the attitudes of the coal users towards stoves and fire seriously. The result was that the adaptation the old woman made, were noticed and fed back to the research team. With that feedback the ignition method could be adapted and that was the key to the wide acceptance.

Flexibility - During the process there is continuous interaction between complex factors. The result is that the progression of the process is not predictable and that it is necessary to be very flexible in progressing from one point to the next. During this project it was necessary to abandon insulation as an option and investigate other options. Also, the changes proposed by the old woman were implemented.

\section{Conclusions}

A different way of lighting a coal fire that can drastically reduce the contribution of coal fires to pollution was developed by using an approach that is fundamentally different to the traditional approach to technology transfer. The following became clear: a) It is not always necessary to provide huge amounts of money to implement and sustain a solution. The adapted method to light a coal stove reduces the fuel cost of households and also the medical costs (to government) because of lower levels of upper respiratory infections.

b) Following a phased approach was crucial to the success of the project. This approach started with field research and development, validation of possible solutions, pilot implementation and only then, full scale implementation. The research phase is of particular importance. The users of technology have valid reasons for doing things the way they do them. These reasons are not always obvious from the outside. It is therefore important to wait with implementation until all the phases are completed.

c) Making the coal users part of the process provided the breakthrough in this project. Without the contribution from the old woman, it is doubtful if any progress would have been made. It also meant taking the coal users and their preferences seriously.

d) Because of the interaction between complex factors, the process of attempting to solve problems by technological means is not predictable and cannot be implemented mechanistically. (This unpredictability is probably also true for attempts to solve problems by economical or political or any other means.)

This new approach can be very effective in attempts to solve problems by technological means. It is important to understand why about $40 \%$ to $50 \%$ of the coal users do not switch over to this new way of lighting a coal fire. This will deepen our understanding of the process and refine the insights gained during this project.

\section{Acknowledgement}

I would like to thank the NOVA Institute for making their reports available to me. The bulk of the content and insights into this paper come from those reports. The studies would not be done and the reports not written were it not for the efforts of many people especially Pieter Swanepoel and Pierre Schoonraad of NOVA, Gerrit Kornnelius of SASOL and Alex Persent and Klaas Moropyane of eMbalenhle. I would also like to thank AS van Niekerk for the many stimulating, enjoyable and (for me) fruitful discussions we had.

\section{Note}

The NOVA Institute is an independent research and development organisation of which the author is a member. The NOVA Institute was established by Dr. AS van Niekerk while professor in Practical Theology at the University of the North. It gave structure to his interest and involvement in development matters over several years. The NOVA Institute tries to bridge the very real gap between the intentions of people and organizations giving development aid and services on the one hand, and the perceptions of the people on the receiving end on the other hand. 


\section{References}

Bentley West and Airshed Planning Professionals. (2004). Study to examine the Potential Socio-Economic Impact of Measures to Reduce Air Pollution from Combustion. Final report submitted to the Trade and Industry Chamber: Fund for Research into Industrial Development Growth and Equity (FRIDGE).

Dalla Palma S. and Zein K. (2004). The DELTA Programme: An Example of Participative Technology Transfer Approach in the South and East Mediterranean Countries. J. Clean Prod. 12, $257-$ 268.

Davis M. and Ward S. (1995). Household Energy Use Patterns in Rural Areas: the Effects of Access to Electricity, p14. Energy and Development Research Centre, University of Cape Town.

Hoets P. (1995). 'My coal stove is my life, without it my life will be meaningless' Electrification of Townships Exploring Some Myths. In Proceedings, Household Energy for Developing Communities: Conference, Exhibition and Workshop, pp. 18-21. VW Conference Centre, Midrand.

Hoets P. (1997). Low Smoke Fuel Macro Experiment Study in Qalabotjha - Villiers. Benchmark Survey part 1. Report submitted to The Department of Minerals and Energy Affairs by Social Surveys Pty (Ltd).

Intergovernmental Panel on Climate Change. (2000) Methodological and Technological Issues in Technology Transfer, chap. 4, p. 117. United Nations Environmental Programme.

Le Roux L.J., Zunckel M. and McCormick S.G. (2005). Laboratory Controlled Quantitative Information About Reduction in Air Pollution Using the 'Basa Njengo Mogogo' Methodology and Applicability to Low-Smoke Fuels (Revised). Report submitted to the Department of Minerals and Energy by the Division of Water, Environment and Forestry Technology, CSIR.

McCarty D., Rieckmann T., Green C., Gallon S. and Knudsen J. (2004). Training Rural Practitioners to Use Buprenorphine: Using the Change Book to Facilitate Technology Transfer. J. Subst. Abuse Treat. 26, 203208.

Qase N., Lloyd P.J.D. and Van Zyl H. (2001). Intervention Potential for Low-Smoke Fuels in the Coal Distribution Chain. Prepared for Department of Minerals and Energy by the Energy and Development Research Centre, University of Cape Town.

R Palmer. (1998). Low Smoke-Fuel Macro Scale Experiment Project Management Report number ES9613. Report submitted to The Department of Minerals and Energy.

Scorgie Y., Burger L.W. and Sowden M. (2001). Analysis, Synthesis and Consolidation of the Qalabotjha and eMbahlenhle Experiments, Including other Investigations. Final Report submitted to the Department of Minerals and Energy by Environmental Management Services CC

The Basa Njengo Magogo Project Team. (2002). Basa Njengo Magogo Pilot Study: Orange Farm. p II. Final report submitted to the Department of Minerals and Energy.

Van Niekerk A.S. (1998). A Place to Feel at Home: a Social Perspective on the Family Hearth in Africa. Boiling Point. Intermediate Technology Development Group, England. Autumn 1998 Number 41, 3-5

Van Niekerk A.S. and Swanepoel P.A. (1999). Sasol Synthetic Fuels: eMbalenhle Air Quality Project, Phase Two, Indoor Air Quality and Desirability. Final report submitted to Sasol Synthetic Fuels, Secunda, by the NOVA Institute.

Van Niekerk A.S. and Swanepoel P.A. (2002) An Assessment of Various Options for Providing LowCost Clean Household Energy. Report submitted to the Department Mineral and Energy: Low Smoke Fuels Programme by the NOVA Institute.

Van Niekerk A.S. and Swanepoel P.A. (2002). Integrated Clean Household Energy - Desirability. Report submitted to the Department Minerals and Energy by the NOVA Institute.

Van Niekerk W.M.K. and Van Niekerk A.S. (2000). A Needs Driven Approach to the Design Process - a Case Study in Combating Pollution in Low Cost Housing. Journal of Energy in Southern Africa. 11, 173-176.

Van Niekerk, AS and Swanepoel, PA. (2002). Domestic Air Quality: Historical Overview. Report submitted to the Department Minerals and Energy: Low Smoke Fuels Programme by the NOVA Institute.

Received 15 April 2005; revised 16 January 2006 